\title{
Rapid biosynthesis of platinum and palladium metal nanoparticles using root extract of Asparagus racemosus Linn.
}

\section{Rajesh W Raut ${ }^{1^{*}}$, Ansari Sana Mohd. Haroon ${ }^{1}$, Yuvraj S Malghe ${ }^{2}$, Bandopant T Nikam², Sahebrao B Kashid²}

${ }^{1}$ Department of Botany, The Institute of Science, 15 Madam Cama Road, Mumbai 32, India

${ }^{2}$ Department of Chemistry, The Institute of Science, 15 Madam Cama Road, Mumbai 32, India

*Corresponding author. Tel: (+91) 22-22844219; E-mail: r_raut@rediffmail.com

Received: 23 November 2012, Revised: 09 January 2013 and Accepted: 12 January 2013

\section{ABSTRACT}

The fabrication of metal nanoparticles is undergoing the revolutionary changes due to their widespread applications in the areas like selective and specific catalysis such as hydrogenation, optoelectronics, semiconductor, sensing and diagnosis. Biologically, the metal nanoparticles are produced using fungi, yeasts, bacteria, algae and plant biomass. The metal nanoparticles synthesized using biological methods include mainly silver and gold. The synthesis of metals like platinum and palladium is still unexplored. In this context we have synthesized Platinum and palladium metal nanoparticles using root extract of Asparagus racemosus Linn. at room temperature. The synthesized metals were characterized using UV-visible spectroscopy, Transmission Electron Microscopy (TEM) and Cyclic Voltammetry (CV) techniques. UV-Visible study revealed that in both cases nanoparticles are produced within $5 \mathrm{~min}$. TEM study shows that metal nanoparticles formed are crystalline in nature and spherical in shape. It also shows that $\mathrm{Pt}$ and $\mathrm{Pd}$ nanoparticles are nearly monodispersed and having a particle size ranging between 1 to $6 \mathrm{~nm}$. CV of the metal nanoparticles shows reversible redox behavior. The method reported for the synthesis of metal nanoparitcles is clean, rapid and ecofriendly. Copyright (C) 2013 VBRI press.

Keywords: Photosensitized synthesis; platinum, palladium; Asparagus racemosus Linn.

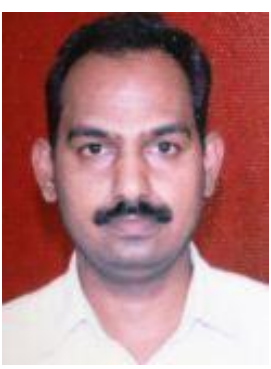

Rajesh W. Raut obtained his $\mathrm{PhD}$ degree in Botany in the subject Nanoscience from University of Mumbai, Mumbai and is currently working as Assistant Professor. Department of Botany, The Institute of Science, Mumbai. He has published several research papers in peer reviewed international journals and conference proceedings. His current research is focused in the area of Green synthesis and characterization of nanomaterials, Alloys and Bimetals. Development of nanobased diagnostic tools, water purification and toxicological evaluation of nanomaterials, Smart materials for skin care and defence.

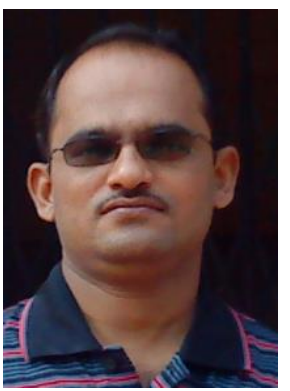

Sahebrao B. Kashid received his B.Sc. (1997) and M.Sc. Analytical Chemistry (1999) from Shivaji University, Kolhapur India. He Joined The Institute of Science Mumbai as Lecturer in Analytical Chemistry (2000). Currently $\mathrm{He}$ is working as Assistant Professor, The Institute of Science Mumbai. $\mathrm{He}$ has received Special Achievement Prize at International conference on Functional materials for Defense DIAT Pune in 2011. Currently he is pursuing Ph.D. in Nanotechnology (Magnetic Nanoparticles).

\section{Introduction}

The use of noble metal nanoparticles (NPs) as catalysts [13] provides new opportunities for the remarkable enhancement in the chemical process industry as they offer an efficient combination of homogenous and heterogeneous catalyst advantages. Solution-phase methods are widely utilized to produce monodisperse metal nanoparticles. The noble metal nanoparticles such as platinum, gold, silver rhodium and palladium are having their application in catalysis, sensing, low temperature fuel cells, biomedicine and cancer therapy due their unique size- and shapedependent optoelectronic properties [4-6].

With significant growth in the interdisciplinary Nanoscience research involving chemists, physicists, biologists and engineers, researchers have focused on the development of sustainable methods for the synthesis of nanomaterials [7]. There is a current drive to integrate all the "green chemistry"'[3] approaches to design environmentally benign materials and processes. Recently, we have synthesized silver metal nanoparticles by an environmentally friendly method without the use of chemical (reducing / stabilizing) reagents $[\mathbf{8 , 9 ]}$. 
Biosynthesis of metal nanoparticles using plant materials is currently under exploration. It has received more attention as a suitable alternative to chemical and physical methods [8-14]. Synthesis of metal nanoparticles using plant extracts is a cost effective method $[\mathbf{1 0 , 1 5 , 1 6 ]}$ and therefore can be used as an economical and viable alternative for the large-scale production of metal nanoparticles. Though chemical reductions are quite well explored, it involves energy intensive operational conditions like high temperature, pressure etc. and also involves numerous toxic chemicals that make the process environment unfriendly. Bioreduction of palladium and platinum is one area which is not much explored, in this respect; Phyto-reduction of precious metals is a promising technology. The phytochemical constituents present in the extracts of the plants may act both as reducing and capping agents in nanoparticle synthesis. To the best of our knowledge till date only few reports [17] are available for palladium and platinum reduction using plant materials. In this paper we report for the first time the bioreduction of platinum and palladium in an aqueous medium at room temperature using root extract of Asparagus racemosus Linn. The synthesized Pt and Pd nanoparticles were characterized using UV-visible spectroscopy, Transmission Electron Microscopy (TEM) and Cyclic Voltammetery(CV).
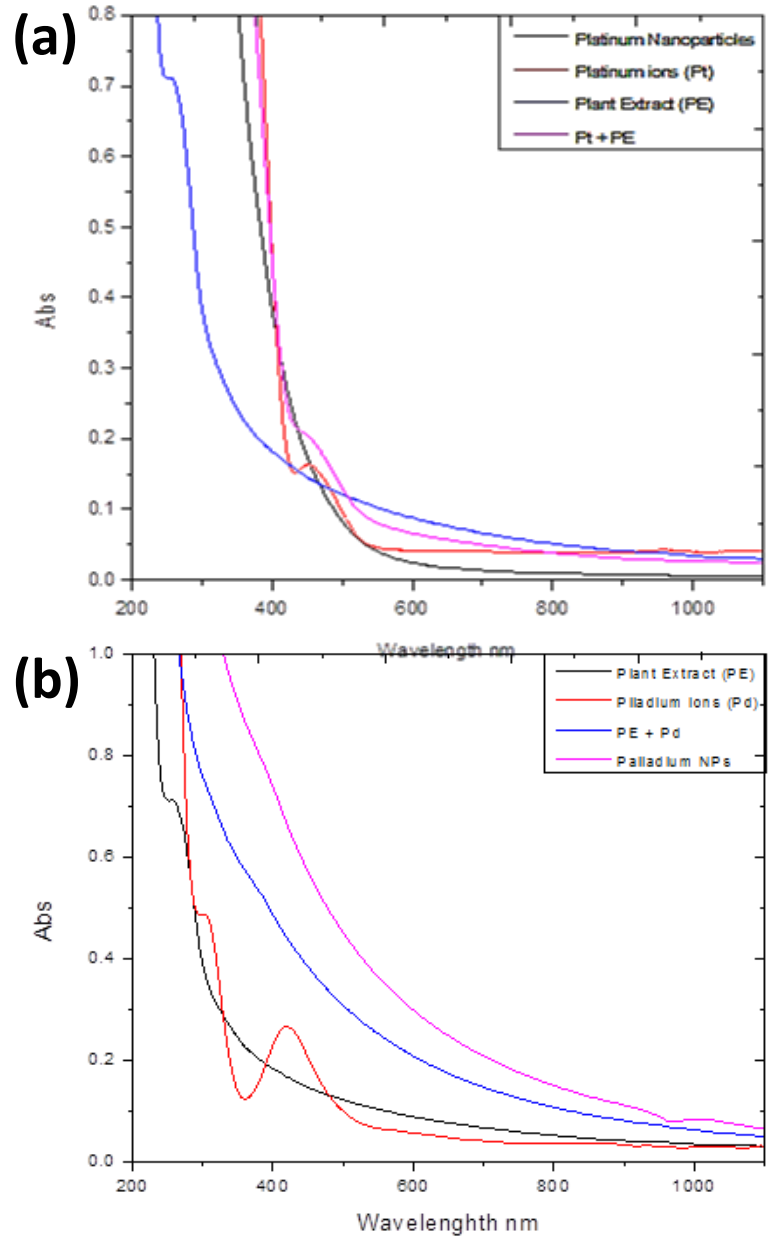

Fig. 1. UV-Visible absorbance spectra of (a) platinum and (b) palladium nanoparticles along with controls.

\section{Experimental}

\section{Materials}

The synthesis of platinum and palladium nanoparticles has been carried out using the root extract of Asparagus racemosus Linn. The tubers of Asparagus racemosus were collected from the nursery of the Mahim Nature Park, Mumbai. The healthy and matured tubers were selected, washed thoroughly. The epidermis was peeled off with the help of a scalpel and the pith was separated with the help of forceps to get the cortex. $5 \mathrm{~g}$ of cortex was homogenized in a mortar and Pestle and suspended in $100 \mathrm{ml}$ of deionized water. The suspended mass was then filtered out; the filtrate obtained contains the bioactive components leached from the tubers. This filtrate was used as the extract for the preparation of platinum and palladium nanoparticles. Metal salts Platinium (IV) chloride, 99.9\% and Palladium (II) chloride 59\% Pd_were purchased from Hi Media India Ltd. and Fisher Scientific respectively and were used as received.

\section{Synthesis of platinum and palladium nanoparticles}

In the separate experiments to the $10 \mathrm{ml}$ of tuber extract, $0.1 \mathrm{ml}$ of $100 \mathrm{mM}$ metal salt (Platinum tetrachloride / Palladium (II) chloride) solution was mixed rapidly. Similarly, two control samples, in one plant extract and in another solution of metal ion were also maintained. The reaction mixtures along with controls were exposed to the sunlight for 5 min under static condition.

\section{$U V$-Vis Spectroscopy studies}

The bioreduction of Platinum and Palladium metal ions in the root extract was monitored by sampling aliquots of the reaction mixture. The aliquots were diluted with double distilled water and spectrum of diluted solution recorded using UV-Visible spectrophotometer (Model- Shimadzu UV 1800) in the wavelength range 190-1100 $\mathrm{nm}$. Baseline correction was made with deionized water. Similarly, the spectra of both the controls were recorded.

\section{Refining of sample}

The completely bioreduced metal nanoparticles were then concentrated by repetitive centrifugation and re-suspension using cold centrifuge [Eppendorf; Model-R5210] compared at 14,000 RPM for $15 \mathrm{~min}$. The pellet was washed and re-dispersed in deionized water thrice to make nanoparticles free from biochemical constituents.

\section{Transmission electron microscopy and selected area electron diffraction measurements}

Samples for TEM were prepared by loading a drop of the refined nanoparticle solution on the carbon coated copper grid followed by drying under Infrared light for $30 \mathrm{~min}$. TEM and SAED measurements were then performed on instrument operated at an accelerating voltage of $200 \mathrm{Kv}$ (Philips; Model CM 200). 
Cyclic voltammetry study

Single scan cyclic Voltammetry was performed using conventional three electrode system. The electrodes used were platinum wire as counter electrode, platinum disc (1 $\mathrm{mm}^{2}$ ) as working electrode and silver-silver chloride as a reference electrode. $5 \mathrm{ml}$ solution of metal nanoparticles was mixed with $1 \mathrm{ml} 0.1 \mathrm{M} \mathrm{KNO}_{3}$ as supporting electrolyte which was followed by purging of nitrogen gas for 2 min to remove dissolved oxygen. The measurements were carried out using potentiostate (VersaSTAT 3 Princeton Applied Research, UK.).

\section{Results and discussion}

\section{$U V$-visible spectroscopy}

Samples of the reaction mixture were diluted with deionized water and then subjected to the spectral measurement. Fig. 1a and 1b show the absorption spectra of reaction mixtures after 5 min along with absorption spectra of two controls (root extract and metal ion solution). After mixing the solution of palladium (II) chloride and platinum tetrachloride with aqueous root extract, the reaction mixture changed rapidly from orange to dark brown in case of palladium and colorless to yellow for platinum (Fig. 2). The new color was ascribed to the excitation of surface plasmon vibrations in the palladium and platinum nanoparticles, which indicates the formation of Pd and Pt nanoparticles directly. After the reduction, the two absorption maxima observed in case palladium chloride (a sharp peak at $260 \mathrm{~nm}$ and a small broad peak around $370 \mathrm{~nm})$. In case of platinum chloride the peak at $440 \mathrm{~nm}$ is disappeared (Fig. 1a and 1b). Since the peaks assigned to metal ions are not found. It is evident that the ions of both the metals are reduced to atoms.

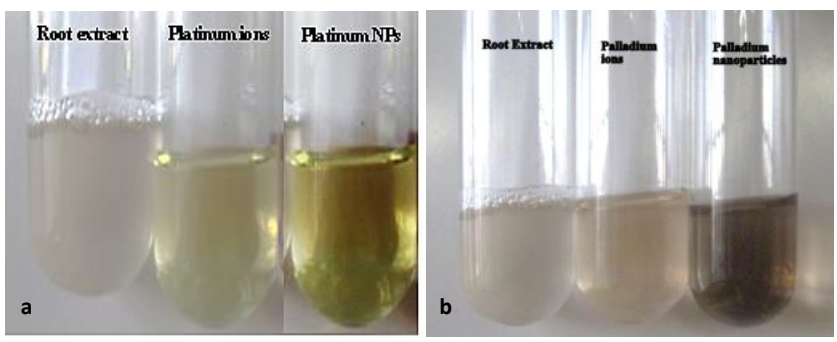

Fig. 2. Reaction mixtures showing colour change (a) platinum (b) palladium.

\section{TEM and selected area electron diffraction studies}

The morphology and size of MNPs ( $M=$ Platinum and Palladium) in the solution was investigated by TEM. Fig. 3a and 3b displays the TEM images and SAED pattern of synthesized nanoparticles synthesized at various magnifications. The resulting NPs are well dispersed but sparse may be due to insufficient concentration of the metal ion precursor. The irregular contour could be observed probably due to the effect of Ostwald ripening during the reaction. In the present case the effect of Ostwald ripening was not so highly pronounced since the particles produced are highly stable. The high stability of the particles is attributed to the presence of bioactive components as capping agents. The different shapes of palladium and platinum nanoparticles and the presence of capping agent need further elucidation by HRTEM. The size of the nanoparticles mainly ranges from 1.0 to $6.0 \mathrm{~nm}$ (Fig. 3a and 3b). The crystalline phase of the synthesized nanoparticles was confirmed by SAED. SAED pattern suggest that the MNPs are essentially crystalline and has characteristic face centered cubic structure.

(a)
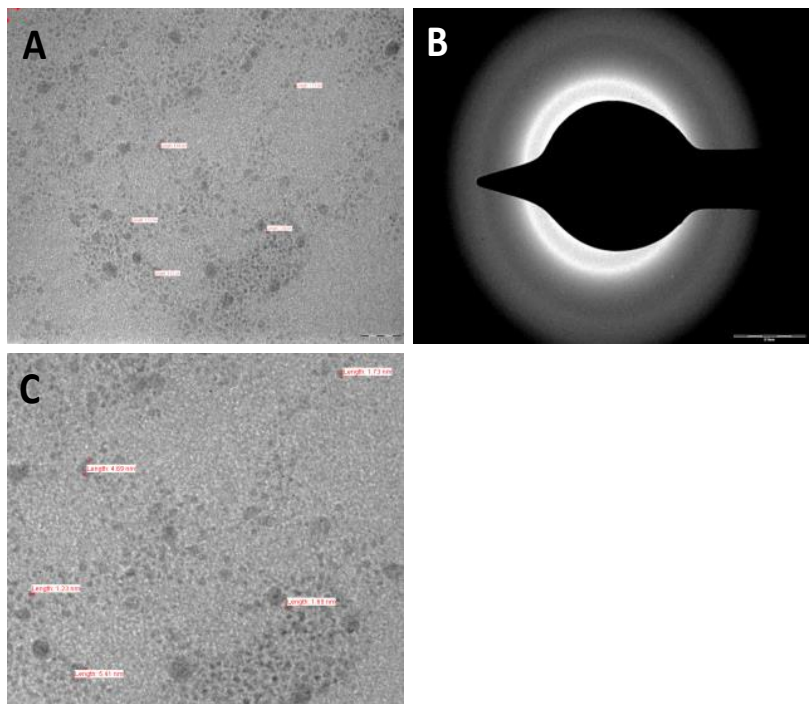

(b)
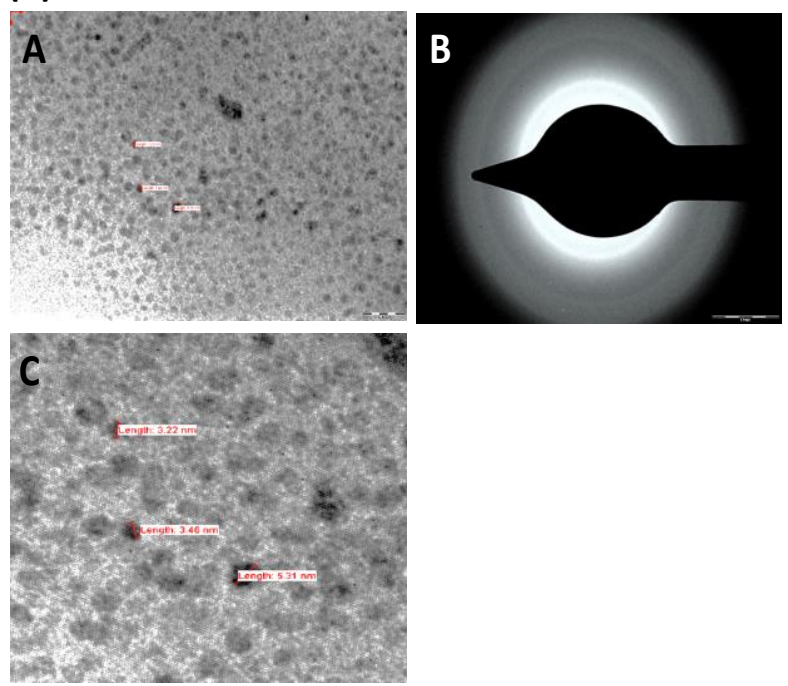

Fig. 3. TEM and SAED pattern of (a) platinum and (b) palladium nanoparticles.

\section{Cyclic voltammetry studies}

The electrochemical measurements were carried out in aqueous solutions at a scan rate of $50 \mathrm{mV} / \mathrm{sec}$. The $\mathrm{CV}$ curves show highly separated redox peaks for both the metal nanoparticles (Fig. 4a and 4b). The presence of anodic and cathodic peaks indicates that the electrode reactions are reversible. However the anodic and cathodic peak separation is greater than the usual reversible redox behavior. Metal particles diffuse towards the electrode surface thereby giving very small peak run on either side. The contribution to the current due to the redox reactions or other functional groups of bioactive compounds is very 
little as the concentration is very low compared to the metal concentration.
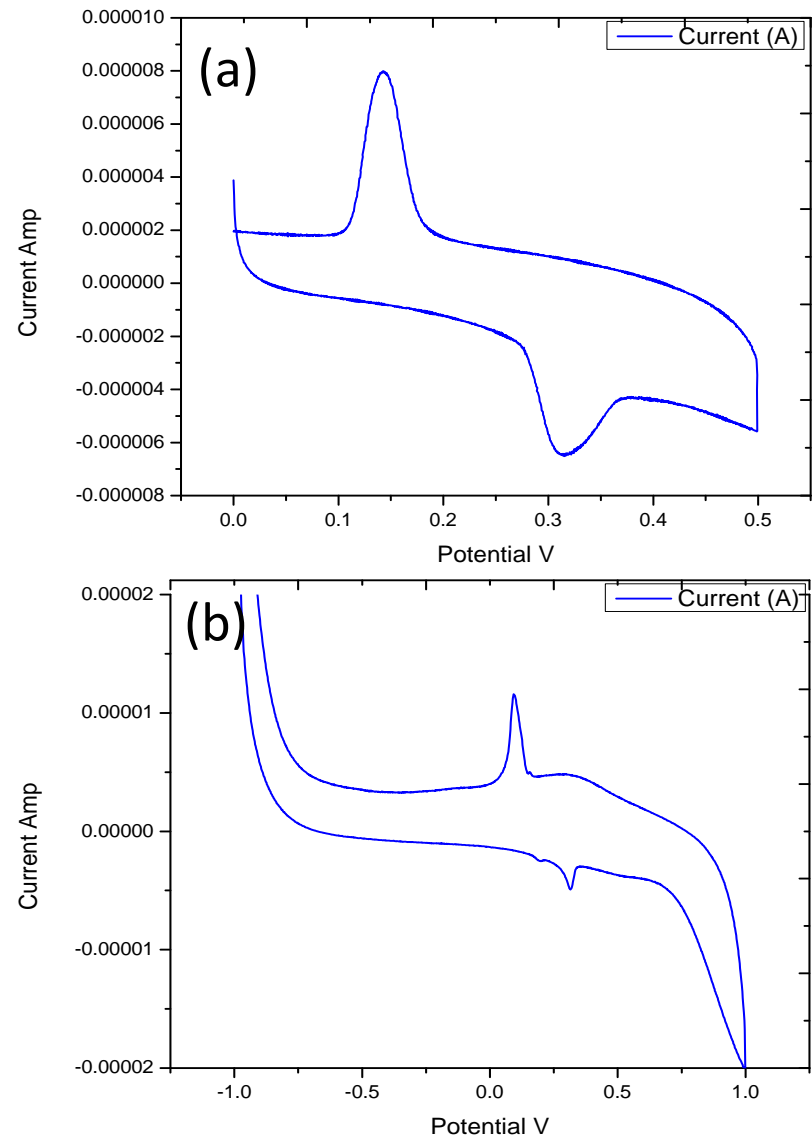

Fig. 4. Cyclic voltammogram of (a) platinum and (b) palladium nanoparticles.

The present study deals with the novel method for the synthesis of platinum and palladium nanoparticles, employing the root extracts of Asparagus racemosus Linn. The biosynthesis of palladium and platinum nanoparticles by various plant material Gardenia jasminoides Ellis [18], coffee and tea extract [19], Cinnamomum camphora leaf extract[20], Solanum trilobatum leaf extract [21], Diopyros kaki leaf extract [22], Curcuma longa tuber extract [23] and banana peel extract [24] has been reported. The biosynthesis of platinum are also reported by Fusarium oxysporum f. sp. Lycopersici [25], cellulosic reducing agents [26] and microbes [17]. In our opinion this is the first report on the rapid photosensitized biosynthesis of platinum and palladium nanoparticle using a biological reducing agent. The rapid and facile bioreduction of platinum ion by the phytochemical methods at room temperature is not yet reported. Whereas the palladium nanoparticles synthesis using plant materials have been reported by very few researchers $[\mathbf{2 0}, \mathbf{2 7}]$. The reported methods involved the boiling of reaction mixture for prolonged periods, strict control of the $\mathrm{pH}$ and addition of stabilizing agents that resulted in the formation of polydispersed product with large particle size. The method reported in the present work offer certain advantages over the methods so far reported as it is free from effect of chemical environment such as $\mathrm{pH}$, temperature, addition of stabilizing agents. The reaction takes place at room temperature eliminating the need of boiling. The phytoreduction in the present study is achieved with minimum energy input. The photosensitization of the reaction mixture triggers phytochemical constituents effecting the reduction of metal ions. The photon serves as an energy source for the shuttling of electrons. It is believed that the various bioactive components such as alkaloids, flavones, steroids, terpenoids, coumarins, lactones, linalools, polysaccharides, amino acids, and proteins existed in plant materials are involved in the reduction process. This method of synthesis by plant extract exhibits the prospective application of plant material as bioreducing as well as stabilizing agents.

\section{Conclusion}

The method of synthesis of $\mathrm{Pt}$ and $\mathrm{Pd}$ nanoparticles reported in the present work is simple, rapid, time saving and environmentally friendly. This method neither require high temperature boiling nor the addition of stabilizing and accelerating agents. This method gives crystalline, monodispersed and very fine metal nanoparticles having a particle size between 1to $6 \mathrm{~nm}$. The photosensitive bioactive compounds like phototropins, flavones may be responsible for rapid reduction and stabilization of the nanoparticles.

\section{Reference}

1. Lee, I.; Albiter, M. A.; Zhang, Q.; Ge, J.; Yin, Y.; Zaera, F. Physical Chemistry Chemical Physics 2011, 13, 2449.

DOI: $10.1039 / \mathrm{c} 0 \mathrm{cp} 01688 \mathrm{~h}$

2. Rajagopalan, R.; Ponnaiyan, A.; Mankidy, P. J.; Brooks, A. W.; Yi, B.; Foley, H. C. Chemical Communications 2004, 2498 DOI: $10.1039 / \mathrm{b} 407854 \mathrm{c}$

3. Shimizu, K.; Wang, J. S.; Wai, C. M. The Journal of Physical Chemistry A 2010, 114, 3956.

DOI: $10.1021 / \mathrm{jp} 907395 \mathrm{z}$

Cao, S.; Mishra, R.; Pilla, S.; Tripathi, S.; Pandey, M.K.; Shah, G.; Mishra, A.K.; Prabaharan, M.; Mishra, S.B.; Xin, J.; Pandey, R.R.; Wu, W.; Pandey, A.C.; Tiwari, A. Carbohydrate Polymers, 2010, 82, 189-194.

Tiwari, A.; Terada, D.; Sharma, P.K.; Parashar, V.; Yoshikawa, C.; Pandey, A.C.; Kobayashi, H.

Analytical Methods, 2011, 3, 217-226.

Shukla, S.K.; Deshpande, S.R.; Shukla, S.K.; Tiwari, A. Talanta, 2012, 99, 283-287.

Parlak, O.; Tiwari, A.; Turner, A.P.F.; Tiwari, A. Biosensors and Bioelectronics, 2013, 49, 53-62.

Sharma, Y.; Tiwari, A.; Hattori, S.; Terada, D.; Sharma, A.K.; Ramalingam, M.; Kobayashi, H.; International Journal of Biological Macromolecules, 2012, 51, 627-631.

4. Albiter, M. A.; Zaera, F. Langmuir The Acs Journal Of Surfaces And Colloids 2010, 26, 16204. DOI: $10.1021 / \mathrm{la} 100753 \mathrm{~g}$

5. Chu, X.; Duan, D.; Shen, G.; Yu, R. Talanta 2007, 71, 2040. DOI: $10.1016 /$ j.talanta.2006.09.013

6. Teow, Y.; Valiyaveettil, S. Nanoscale 2010, 2, 2607. DOI: $10.1039 / \mathrm{c} 0 \mathrm{nr} 00204 \mathrm{f}$

7. Tiwari, A.; Mishra, A. K.; Kobayashi, H.; Turner, A. P. F. Wiley Scrivener, 2012; p. 864. DOI: $10.1002 / 9781118311974 . \operatorname{ch} 14$

8. Raut, R. W.; Lakkakula Jaya R; Niranjan S, K.; Mendhulkar Vijay D; Kashid, S. B.; Kashid B, S. Current nanoscience 2009, 5, 117. DOI: $10.2174 / 157341309787314674$

9. Raut, R. W.; Kolekar, N. S.; Lakkakula, J. R.; Mendhulkar, V. D.; Kashid, S. B. Nano-Micro Letters 2010, 2, 106. DOI: $10.5101 / \mathrm{nml} . \mathrm{v} 2 \mathrm{i} 2 . \mathrm{p} 106-113$

10. Ankamwar, B.; Damle, C.; Ahmad, A.; Sastry, M. Journal of Nanoscience and Nanotechnology 2005, 5, 1665. DOI: $10.1166 / \mathrm{jnn} .2005 .184$ 
11. Kaviya, S.; Santhanalakshmi, J.; Viswanathan, B.; Muthumary, J.; Srinivasan, K. Spectrochimica acta Part A Molecular and biomolecular spectroscopy 2011, 79, 594.

DOI: $\underline{10.1016 / j . s a a .2011 .03 .040}$

12. Njagi, E. C.; Huang, H.; Stafford, L.; Genuino, H.; Galindo, H. M.; Collins, J. B.; Hoag, G. E.; Suib, S. L. Langmuir : the ACS journal of surfaces and colloids 2011, 27, 264.

DOI: $10.1021 / \mathrm{la} 103190 \mathrm{n}$

13. Varshney, R.; Bhadauria, S.; Gaur, M. S. Advanced Materials Letters 2010, 1,232 .

DOI: 10.5185 /amlett.2010.9155

14. Christensen, L. Advanced Materials Letters 2011, 2, 429. DOI: $10.5185 /$ amlett.2011.4256

15. Jha, A. K.; Prasad, K.; Kulkarni, A. R. Colloids and surfaces $B$ Biointerfaces 2009, 73, 219.

DOI: $10.1016 / \mathrm{j}$. colsurfb.2009.05.018

16. Song, J. Y.; Kim, B. S. Bioprocess and biosystems engineering 2009, 32,79 .

DOI: $10.1007 / \mathrm{s} 00449-008-0224-6$

17. Narayanan, K. B.; Sakthivel, N. Advances in colloid and interface science 2010, 156, 1. DOI: $10.1016 /$ j.cis.2010.02.001

18. Jia, L.; Zhang, Q.; Li, Q.; Song, H. Nanotechnology 2009, 20, 385601

DOI: $10.1088 / 0957-4484 / 20 / 38 / 385601$

19. Nadagouda, M. N.; Varma, R. S. Green Chemistry 2008, 10, 859. DOI: $10.1039 / \mathrm{b} 804703 \mathrm{k}$

20. Yang, X.; Li, Q.; Wang, H.; Huang, J.; Lin, L.; Wang, W.; Sun, D.; Su, Y.; Opiyo, J. B.; Hong, L.; Wang, Y.; He, N.; Jia, L. Journal of Nanoparticle Research 2010, 12, 1589.

DOI: $\underline{10.1007 / \mathrm{s} 11051-009-9675-1}$

21. Kanchana, A.; Devarajan, S.; Ayyappan, S. R. Nano-Micro Letters 2010, 2,169

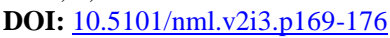

22. Song, J. Y.; Kwon, E.-Y.; Kim, B. S. Bioprocess and Biosystems Engineering 2010, 33, 159.

DOI: $10.1007 / \mathrm{s} 00449-009-0373-2$

23. Sathishkumar, M.; Sneha, K.; Yun, Y. International Journal of Materials Sciences 2009, 4, 11

24. Bankar, A.; Joshi, B.; Kumar, A. R.; Zinjarde, S. Materials Letters 2010, 64, 1951.

DOI: $10.1016 /$ j.matlet.2010.06.021

25. Riddin, T. L.; Gericke, M.; Whiteley, C. G. Nanotechnology 2006, 17,3482 .

DOI: $10.1088 / 0957-4484 / 17 / 14 / 021$

26. Benaissi, K.; Johnson, L.; Walsh, D. A.; Thielemans, W. Green Chemistry 2010, 12, 220

DOI: $10.1039 / \mathrm{b} 913218 \mathrm{j}$

27. Sathishkumar, M.; Sneha, K.; Kwak, I. S.; Mao, J.; Tripathy, S. J.; Yun, Y.-S. Journal of Hazardous Materials 2009, 171, 400.

DOI: $\underline{10.1016 / j . j h a z m a t .2009 .06 .014}$

\section{Advanced Materials Letters}

\section{Publish your article in this journal}

ADVANCED MATERIALS Letters is an international journal published quarterly. The journal is intended to provide top-quality peer-reviewed research papers in the fascinating field of materials science particularly in the area of structure, synthesis and processing, characterization, advanced-state properties, and applications of materials. All articles are indexed on various databases including DOAJ and are available for download for free. The manuscript management system is completely electronic and has fast and fair peer-review process. The journal includes review articles, research articles, notes, letter to editor and short communications. 